\title{
A gestão do trabalho na estratégia saúde da família: (des)potencialidades no cotidiano do trabalho em saúde
}

\section{Labour management in the family health strategy: (non-)potentialities in the everyday work of healthcare}

\author{
Heletícia Scabelo Galavote \\ Universidade Federal do Espírito Santo. Departamento de Ciên- \\ cias da Saúde. Programa de Pós-Graduação em Saúde Coletiva. \\ Vitória, ES, Brasil. \\ E-mail: heleticiagalavoteळyahoo.com.br \\ Túlio Batista Franco \\ Universidade Federal Fluminense. Niterói, RJ, Brasil. \\ Università Di Bologna. Bologna, Italia. \\ E-mail: tuliofranco@gmail.com \\ Paula de Souza Silva Freitas \\ Universidade Federal do Espírito Santo. Programa de Pós-Gradu- \\ ação em Saúde Coletiva. Vitória, ES, Brasil. \\ E-mail: paulinhassf_enfळyahoo.com.br

\section{Eliane de Fátima Almeida Lima} \\ Universidade Federal do Espírito Santo. Departamento de Enfer- \\ magem. Vitória, ES, Brasil. \\ E-mail: elianelima66œgmail.com

\section{Ana Cláudia Pinheiro Garcia} \\ Universidade Federal do Espírito Santo. Programa de Pós-Gradu- \\ ação em Saúde Coletiva. Vitória, ES, Brasil. \\ E-mail: anacpgarciaœhotmail.com

\section{Maria Angélica Carvalho Andrade} \\ Universidade Federal do Espírito Santo. Departamento de Me- \\ dicina Social. Programa de Pós-Graduação em Saúde Coletiva. \\ Vitória, ES, Brasil. \\ E-mail: geliandradeœhotmail.com

\section{Rita de Cássia Duarte Lima} \\ Universidade Federal do Espírito Santo. Departamento de Enfer- \\ magem. Programa de Pós-Graduação em Saúde Coletiva. Vitória, \\ ES, Brasil. \\ E-mail: ritacdløuol.com.br
}

\section{Correspondência}

Heletícia Scabelo Galavote

Rodovia BR I0I Norte, Km 60, Bairro Litorâneo. São Mateus, ES,

Brasil. CEP 29932-540.

\section{Resumo}

Este artigo discute os limites e as potencialidades da gestão do trabalho na Estratégia Saúde da Família, a partir do discurso dos gestores formais, ocupantes de cargos de autodireção na gestão municipal da saúde. Trata-se de um estudo do tipo descritivo, exploratório, com abordagem qualitativa. Foram entrevistados 72 gestores, por meio de entrevista semiestruturada com base em um roteiro guia, em 36 municípios. A análise dos dados foi fundamentada no método de análise do discurso. Os resultados apontam limites à constituição da gestão do trabalho nos municípios, com destaque para a interferência política, baixa provisão de profissionais médicos, inoperância das redes de atenção à saúde e o controle financeiro e orçamentário no bojo da macropolítica. Dentre as potencialidades, são citados o vínculo trabalhador-usuário, a gestão compartilhada, o controle de metas e resultados e o Programa Mais Médicos. Nesse sentido, o maior desafio na ativação da potência para a ação do trabalhador consiste na inovação por meio de novos modos de produzir a gestão do trabalho, com base na cogestão com espaços dialógicos de tomada de decisão que tenham a potência de disparar novas formas de vida no gestor e no trabalhador, através da democratização da tomada de decisão.

Palavras-chave: Gestão do Trabalho; Saúde da Família; Trabalhadores; Gestor de Saúde. 


\section{Abstract}

This article discusses the limits and potentialities in the management of labor in the Family Healthcare Strategy, starting on the discourse for the formal managers, officers in self-direction positions at the Municipal Healthcare Management. This is a descriptive, exploratory study with a qualitative approach. Seventy two managers, in 36 Municipalities, were interviewed using a semi-structured survey based on a guiding script. The data analysis was founded on the Discourse Analysis Method. The results pointed to the limits of the constitution of labor management in the municipalities, highlighting political interference, low provision of medical professionals, healthcare attention grids that are inoperative, and the financial and budgetary control in the center of macropolitics. Out of the potentialities mentioned, the bond between worker and client, the shared-management, the control of goals and results, and the More Physicians (Mais Médicos) Program were cited. In this sense, the greatest challenge in the activation of power to the worker's action is innovation through new ways of producing the management of the work, based on co-management with dialogical spaces of decisionmaking that have the power to trigger new forms of life in the manager and the employee, through the democratization of decision-making.

Keywords: Labor Management; Family Health; Workers; Healthcare Management.

\section{Introdução}

Um modelo de atenção à saúde deve ter seu foco no conteúdo do sistema de saúde representado pelas práticas, e não apenas no continente enquanto infraestrutura, gestão e financiamento. Essa designação refere-se essencialmente às formas de organização dos serviços, com base em tecnologias estruturadas para a resolução de problemas e atendimento das necessidades de saúde. Paim (2012), ao apresentar os diferentes modelos tecnoassistenciais vivenciados no país, destaca: o médico hegemônico com medicalização dos problemas e privilégio da dualidade saúde/doença; o Programa Saúde da Família (PSF), com intervenção focada em pobres e excluídos; tecnologia da programação em saúde; ações territorializadas; prevenção de riscos e agravos; e a Estratégia Saúde da Família (ESF), com interface entre as combinações tecnológicas da oferta organizada, distritalização, vigilância à saúde e reorganização dos processos de trabalho.

O PSF surge, em 1994, como um modelo de atenção à saúde de caráter verticalizado e prescritivo, no contexto da Atenção Primária Seletiva, constituída por programas focalizados e diretivos, com uma cesta restrita de serviços direcionados às populações pobres e vulneráveis. Essa concepção de Atenção Primária à Saúde (APS) difere daquela proposta na Conferência de Alma Ata, em 1978, que tinha o propósito de instituir uma atenção abrangente ou integral, a partir da necessidade de enfrentar os determinantes sociais de saúde, com caráter universal. Giovanella e Mendonça (2012) associam o surgimento da APS seletiva ao contexto mundial adverso de baixo crescimento econômico, considerando a perspectiva de redução de custos das agências internacionais de financiamento, como, por exemplo, o Banco Mundial. A proposição da lógica de contenção dos gastos foi designar um pacote de intervenções de baixo custo para combater as doenças em países em desenvolvimento.

No Brasil, os esforços para a superação dessa herança da APS seletiva tiveram como proposta a mudança do termo APS por Atenção Básica, enquanto um nível de atenção do SUS, essencial, fundamental e primordial, diferencia-se do concei- 
to seletivo restrito de primitivo e simples. Assim, o PSF, enquanto programa vertical e restrito da APS seletiva, experiencia uma reformulação para um modelo de atenção da APS integral, admitindo o caráter de uma estratégia de substituição do modelo de atenção à saúde, com a organização do Sistema Único de Saúde (SUS) em processo de municipalização, integralidade do cuidado, participação da comunidade e reorganização das práticas de trabalho (Giovanella; Mendonça, 2012). Em 1997, o Ministério da Saúde atribui à Saúde da Família o escopo de estratégia para a reorientação do modelo assistencial, com um enfoque na proposta de ação no contexto da atenção básica e como porta de entrada do sistema (Brasil, 1997).

Franco e Merhy (2003) referem que a matriz teórica do PSF está circunscrita ao campo da vigilância em saúde de territórios, centrando o processo de trabalho às normas e prescrições de caráter higienista, constituindo uma linha paralela ao modelo médico hegemônico. Para os autores, para além da proposição de uma conceituação de estratégia, o PSF cometeu um "erro de saída", aliado à herança de uma proposta da APS seletiva e desvinculada da potência de transformação que se refere à reestruturação dos processos de trabalho em saúde. A despotencialização da proposta como um novo modelo assistencial está contida na ênfase da mudança de estrutura, sem que haja ressignificações concisas nos microprocessos do trabalho em saúde.

Gil (2006) reconhece o crescimento da ESF no Brasil, mas ressalta que ela apresenta desafios para sua viabilização, enquanto estratégia estruturante de sistemas municipais, no que se refere às práticas profissionais que deveriam estar centradas no vínculo, responsabilização, integralidade e trabalho em equipe; e à gestão burocratizada do sistema, com normatizações, lógica quantitativa de produção de procedimentos, baixa capacidade de inovação gerencial e desarticulação com os demais pontos de atenção da rede de serviços.

Nesse cenário, os trabalhadores da saúde constituem um dos desafios à implementação dos modelos de atenção à saúde no âmbito do SUS, especialmente na atenção básica, especificamente na ESF, visto que a reorientação dos modelos vigentes será pos- sível a partir da organização das práticas em saúde no espaço da micropolítica. Fortuna (2002, p. 273) aponta que os trabalhadores da saúde são o alvo das discussões de inovações no SUS no que se refere à organização do trabalho. Propõe um distanciamento do termo "recursos humanos em saúde", proposto por alguns autores e políticas ministeriais, reconhecendo que o trabalhador é um "sujeito social em processo de relação”, e não pode ser equiparado a um mero recurso da instituição, semelhante a recursos materiais e físicos.

A gestão do trabalho pode ser compreendida apenas sob o formato administrativo, pautado em situações de mando e no controle prescritivo da organização dos processos de trabalho, no campo da macropolítica, mas também pode ser uma ação cotidiana do trabalhador, no espaço da micropolítica, a partir do reconhecimento de que todos os trabalhadores são gestores do seu próprio trabalho, exercendo graus de liberdade na organização e execução de suas práticas.

O território da gestão do trabalho é constituído pela imanência entre macro e micropolítica, de forma que alguns trabalhadores ocupam cargos de autodireção do governo municipal e estão situados em um espaço de produção de um poder que tangencia o saber-fazer de outros atores (Franco, 2013).

Um dos grandes desafios à gestão do trabalho em saúde é conduzir a "potência andante" enquanto estímulo à liberdade de ação e criação de cada trabalhador, no sentido de que o projeto técnico-ético e político a serviço do cuidado deva ser também um projeto do trabalhador operante, constituindo sua subjetividade na proposição de novos dispositivos nos serviços de saúde, em contraposição à serialização de práticas rudimentares. Assim,

É possível na gestão do trabalho em saúde manter o trabalhador com alta potência para agir no mundo do cuidado, que é também um mundo social e afetivo, e possibilitar que o trabalhador produza no outro [...] alta potência vital (Franco, 2013, p. 250).

Dessa forma, este estudo tem por objetivo analisar a gestão do trabalho na ESF através da identificação de potencialidades e limites apontados 
pelos gestores formais, ou seja, aqueles ocupantes de cargos de autodireção na gestão da ESF em nível municipal. É sabido que esses gestores transitam no espaço da macro e micropolítica, e que identificam, a partir do lugar que ocupam, aspectos importantes da gestão do trabalho que são imprescindíveis para a implementação dos modelos de atenção, especialmente a ESF, e que têm a possiblidade de gerar potência ou impotência nos trabalhadores na condução do modelo assistencial proposto.

\section{Estratégias metodológicas}

Trata-se de um estudo do tipo descritivo, exploratório, com abordagem qualitativa. Foi realizado em municípios que compõem o estado do Espírito Santo (ES).

Para a determinação da amostra foi realizado sorteio aleatório dos municípios, considerando estratos por tamanho da população (menor e maior que 50.0oo habitantes) e também pelas doze Microrregiões de Saúde. Foram sorteados três municípios por microrregiões e, além disso, sete municípios com mais de 50.000 habitantes. Ao todo foram selecionados 39, ou seja, $50 \%$ dos municípios do estado. Em virtude de aspectos referentes ao acesso geográfico e à concessão de autorização para a realização deste estudo, foi verificada uma perda de três municípios.

Foram convidados a participar do estudo os seguintes gestores: secretário municipal de saúde; coordenador municipal da Estratégia Saúde da Família e coordenador da Atenção Primária à Saúde, totalizando 72 participantes que foram referidos pela letra G, em grafia maiúscula, seguida por números arábicos que correspondem à ordem de transcrição das entrevistas.

A coleta de dados foi realizada, entre janeiro e dezembro de 2014, mediante entrevista individual com os gestores em seus locais de trabalho, com a utilização de um formulário de identificação e um roteiro de entrevista semiestruturado.

Os dados provenientes das entrevistas foram transcritos e o conteúdo produzido foi analisado a partir da Análise do Discurso, que tem por fundamento interpretar o processo de produção e inter- pretação do discurso, unificado através de um texto para fins de análise (Minayo, 2014).

As etapas de organização e análise dos dados foram: transcrição das entrevistas, que foi realizada de forma detalhada, não sintetizando a fala, ou corrigindo-a; e evocação de um espírito da leitura cética com a codificação dos dados, organizando as categorias de interesse. Para este estudo, os resultados e a discussão dos dados foram organizados em categorias analíticas empíricas, a saber, potencialidades e limites da gestão do trabalho na ESF, a fim de facilitar a análise e a observância das nuances do objeto em estudo.

O projeto de pesquisa foi submetido à apreciação do Comitê de Ética em Pesquisa do Centro de Ciências da Saúde da Universidade Federal do Espírito Santo, sendo aprovado com o número de parecer: 363867 de $28 / 08 / 2013$.

\section{Resultados e discussão}

\section{Caracterização sociodemográfica e profissional dos gestores}

São predominantemente do sexo feminino (66,67\%), com idade média de 38,8 anos e nível de escolaridade compatível com ensino superior completo (95,83\%).

Fleury (2014), em um estudo sobre o impacto da descentralização no perfil dos gestores municipais, relata dados que indicam a expansão da ocupação de mulheres nos cargos de liderança, com predomínio dessa população no seu universo de estudo, o que complementa os dados de gênero encontrados neste estudo. Aponta também a presença de gestores jovens na faixa etária de até 40 anos, o que demonstra motivação dos jovens para os cargos de liderança com desafios diversos.

A maioria ocupa o cargo de secretário municipal de saúde $(45,83 \%)$, seguidos por coordenadores municipais da Atenção Primária à Saúde (40,28\%) e coordenadores municipais da ESF (13,89\%), com $65,28 \%$ atuantes no cargo com tempo de duração entre 1 a 6 anos, seguidos pelos gestores atuantes há menos de um ano (29,17\%). 
$59,72 \%$ têm experiência anterior de trabalho em ESF e $65,28 \%$ já exerceram algum cargo de gestão na saúde, o que representa um requisito importante para o acesso ao cargo.

Quanto à formação profissional complementar dos gestores, observou-se que $66,67 \%$ haviam realizado algum curso sobre saúde da família, e 51,39\% não possuíam formação em gestão em saúde. No que se refere à variável ter realizado algum curso de capacitação para o cargo, percebe-se que $55,56 \%$ não receberam nenhum tipo de formação específica para a função exercida. Trinta e dois gestores relatam que participaram de cursos específicos para o cargo, oferecidos pela esfera estadual (29,17\%), no formato de oficinas: do plano diretor da Atenção Primária e de gestão e financiamento do SUS.

\section{Potencialidades da gestão do trabalho}

Na identificação dos pontos favoráveis, vislumbrados na gestão do trabalho das equipes da ESF, foram apontados: o vínculo profissional-usuário, a disponibilidade satisfatória dos insumos e equipamentos, a infraestrutura das Unidades de Saúde da Família (USF), a oferta de profissionais para comporem equipes incompletas, o trabalho em equipe, a organização dos processos de trabalho, o Programa Mais Médicos e a gestão compartilhada.

O vínculo foi valorizado como um dispositivo para o sucesso das ações de reorganização e resolutividade do processo de trabalho na ESF.

O vínculo com a comunidade, conhecer a população que eles trabalham pra desenvolver o trabalho de acordo com a realidade que eles têm pra desenvolver o trabalho $\left(\mathrm{G}_{3}\right)$.

Constitui uma das diretrizes operacionais da ESF, como uma aposta no estabelecimento de um encontro em potencial entre o usuário e o trabalhador, o que constitui o cerne do trabalho em saúde. Franco e Merhy (2003) reconhecem o vínculo como uma ferramenta de trabalho que se situa no campo das tecnologias leves em saúde, promotora de relações e que tem a potência de garantir a face humanitária, imprescindível ao trabalho em saúde.
Para os autores, a tríade acolhimento, vínculo e responsabilização, enquanto diretrizes do modelo assistencial, operam principalmente por tecnologias leves produtoras do cuidado e contribuem para uma nova postura dos profissionais na relação com os usuários, permitindo a organização de novos processos coletivos de subjetivação no espaço das equipes de saúde.

Magnago e Pierantoni (2015, p. 14) referenciam o vínculo como um pilar da ESF, já que é promotor de "efetividade das ações assistenciais, facilita a continuidade do acompanhamento terapêutico e favorece a participação ativa do usuário durante o cuidado". Na verdade, a natureza da relação que é estabelecida entre o trabalhador e o usuário determinará o tipo de vínculo produzido, que pode ser de potência ou de fragilização, posto que esse encontro pode estar orientado pela valorização da autonomia e protagonismo dos atores, ou ao contrário, ser de amortecimento da potência para ação desses atores, no sentido de que o usuário é objetificado por um processo de trabalho voltado para as práticas biomédicas e centrado nas tecnologias duras, enquanto normas e equipamentos, e leve-duras inscritas nos saberes instituídos.

A estrutura física adequada das unidades de saúde e a provisão eficaz de equipamentos e insumos foram referidas como facilitadores do trabalho de gestão.

Estrutura, infraestrutura, pessoal, pessoal qualificado, pessoal em quantitativo adequadoe suporte administrativo das unidades. Nós temos todas as unidades aqui muito bem estruturadas, não temos nenhuma Estratégia de Saúde da Família em casas adaptadas. Todas elas foram construídas para ser Estratégia de Saúde da Família (G6).

Mendonça et al. (2010), ao analisar as dificuldades da gestão do trabalho na ESF, aponta a necessidade de intervenções gerenciais nas USFs, através da promoção de condições de trabalho adequadas às atividades desenvolvidas, por meio da reestruturação das dependências físicas, oferta de insumos em quantidade suficiente e segurança 
física e ambiental. A autora salienta que a ênfase na adequação dos elementos estruturais dos serviços constitui um componente facilitador do trabalho de gestão em saúde.

G8 relata o engajamento dos gestores municipais na condução e organização do processo de trabalho das equipes da ESF, e aponta como método para o sucesso das intervenções a cobrança de metas, controle da carga horária e dos resultados.

Um dos pontos favoráveis que a gente tem é a intenção que o executivo municipal tem que o PSF dê certo, então ele cobra muito resultado do $P S F$, tem que funcionar, tem que funcionar, ele cobra carga horária, tem que conversar com o médico, tem que trabalhar, é isso, o prefeito ele cobra demais (G8).

Para o gestor, a inovação dos processos gerenciais é possível mediante o controle do processo de trabalho como um meio para o alcance da sua imagem objetivo, que representa os resultados considerados satisfatórios, especialmente, expresso por dados quantitativos de produção de consultas e procedimentos. Nessa perspectiva, o trabalhador é visto como um mero executor das ações propostas pela gestão centralizada na figura do secretário municipal de saúde e do coordenador da ESF. No entanto, no espaço da micropolítica, enquanto o agir cotidiano dos sujeitos, o trabalho em saúde é altamente potente na produção de criatividade, autonomia e inventividade, configurando uma tensão entre o poder mandatório dos gestores e o autogoverno dos trabalhadores, o que demonstra a impossibilidade de controle absoluto do fazer em saúde pelas amarras da gestão formal do trabalho.

A gestão por resultados, garantida mediante estratégias de disciplina e controle, é priorizada como uma forma de organização dos diferentes trabalhos e representa o trabalho prescrito por normas, saberes e poderes instituídos no bojo da organização, que pode ser designado também como trabalho morto, instituído por meio de tecnologias de trabalho duras, como equipamentos e normalizações organizacionais, e leve-duras, por meio de saberes bem estruturados, que buscam aprisionar o trabalho vivo do trabalhador. Este tem uma potência criadora, pode ser inventivo; e está em ação (Merhy et al, 2014).

Existe uma constante tensão entre a autonomia e o controle no mundo das organizações de saúde, que é considerado um território tensional em si, já que opera com alto grau de incerteza, marcado pelas subjetividades dos atores em cena, sendo um "espaço de intervenção de sujeitos coletivos inscritos a partir de suas capacidades de se autogovernarem, disputando o caminhar do dia a dia, com as normas e regras instituídas para o controle organizacional" (Merhy, 1999, p. 309).

Cecílio (apud Barros, 2007) alerta sobre a constituição de uma gestão pautada em princípios funcionalistas, que, aliados a uma ideia de gestor moralmente comprometido com a construção do SUS, produzem o gestor funcional/moral, aquele que em sua essência reconhece o trabalhador apenas pelas funções que executa no serviço, agindo de forma a expropriá-lo do seu trabalho vivo através de uma racionalidade única nos modos de organizar o cuidado e a gestão em saúde.

O Programa Mais Médicos é referido como um fator positivo na oferta de profissionais médicos para a ESF e na organização do trabalho com melhorias no acesso da população à consulta médica e na qualidade do atendimento das necessidades de saúde.

Eu vejo que os profissionais que estão chegando, hoje a gente tem 19 cubanos, isso mudou bastante o perfil também do atendimento [...], com os profissionais de Cuba a gente tem visto que não existe essa questão do atendimento, eles atendem até o último paciente que encontram na unidade (G57).

[...] o Mais Médicos tá fazendo diferença para o Brasil, porque o Mais Médicos faz um diagnóstico diferente, diferente do médico brasileiro, que geralmente pergunta o que a pessoa tá sentindo sem olhar pra paciente eles fazem a receita, isso eu acho dificuldade porque não fica um diagnóstico [...] o médico cubano tem paciência de anotar, uma consulta de 20, 30 minutos (G20). 
O Programa Mais Médicos, criado por força da Lei 12.871/2013, está alicerçado no objetivo de diminuir a carência de médicos nas regiões prioritárias para o SUS, a fim de reduzir as desigualdades regionais na área da saúde, bem como fortalecer a prestação de serviços na atenção básica em saúde no Brasil e aprimorar a formação médica no país (Brasil, 2013). Para os gestores, além da provisão de médicos para atuarem na ESF, o referido Programa representa a emergência de uma clínica ampliada sob um formato de mudança do objeto e do objetivo do cuidado na relação médico e usuário, sendo o último reconhecido como cidadão pleno detentor de autonomia e agente no encontro com o trabalhador da saúde. 0 médico cubano, por exemplo, surge como um ator que concede ao usuário espaços de escuta e responsabilização, em uma relação de interesse para além do componente orgânico sintetizado na instância doença (Campos, 2007).

Collar e colaboradores (2015) afirmam que o Programa foi desenvolvido a partir da concepção de que a falta de profissionais médicos e o acesso e qualidade na Atenção Básica são requisitos importantes para os avanços no SUS. Fundamenta-se na equidade no acesso à cobertura de saúde de forma qualificada e no estímulo à valorização dos diferentes atores: gestores, usuários e trabalhadores. $\mathrm{Na}$ concepção dos gestores, a provisão de profissionais médicos na ESF seria um fator imprescindível para a organização das redes de atenção à saúde e legitimação da proposta do modelo de atenção à saúde, com valorização do quantitativo de atendimentos e promoção de um atendimento mais qualificado, compreendendo a baixa capacidade resolutiva da atenção básica como associada à carência de profissionais médicos.

O trabalho em equipe, na visão do gestor, possibilita a pactuação de compromissos e permite aos trabalhadores espaços de reflexão e de atuação em consonância com a gestão rumo à consolidação da ESF no município. G38 reconhece que os trabalhadores são gestores também da ESF, conduzindo e reinventando seus processos de trabalho, e os espaços coletivos são valorizados na condução do trabalho e na proposição de tarefas.
Sem equipe não há trabalho. Então, trabalhar em equipe para mim é o principal. Nós iniciamos reuniões de gestão, onde combinamos todas as coordenações aqui para apresentar para eles qual o momento de trabalho. Então, é nisso que estamos trabalhando $\left(\mathrm{G}_{3} 8\right)$.

O reconhecimento pelo gestor de que "sem equipe não há trabalho" remete à constatação de que todo trabalho em saúde é um trabalho em rede, formada por fluxos e conexões estabelecidas entre os trabalhadores, destes com os usuários e de todos com os serviços de saúde. As microrredes, mesmo implícitas, vão sendo tecidas pelo cruzamento de saberes, fazeres, tecnologias e subjetividades, de forma harmoniosa ou não. "É como se não existisse uma autossuficiência no trabalho em saúde, ou seja, nenhum trabalhador poderia dizer que sozinho consegue ter uma resolutividade que seja satisfatória” na execução de um projeto terapêutico centrado nas necessidades de saúde dos usuários (Franco, 2006, p. 466). 0 trabalhador transita por territórios construídos por multiplicidades de agires e atores, de forma que a gestão dessas microrredes, que constituem o trabalho em saúde, é feita pelos seus protagonistas, com alto caráter autogestionário, o que entra em contradição com o discurso de G38, que aponta a determinação do momento de trabalho das equipes como uma atribuição da gestão formal do trabalho, e não dos trabalhadores nos cenários reais de práticas.

0 trabalho em rede, nesse contexto, pode representar o compartilhamento de atos e saberes como possibilidade de encontro de potência entre os trabalhadores, ou ao contrário, ser uma rede modelar, que reproduz sistemas normativos de serialização das práticas, ignorando as singularidades expressas no campo da micropolítica.

G69 refere como ponto favorável para a inovação das práticas de gestão do trabalho, a ideia da gestão compartilhada, com tomada de decisão coletiva que faça sentido para o trabalhador operante.

Assim, o ponto mais favorável é essa gestão compartilhada. Porque assim, é... não se toma decisões de cima pra baixo e que as pessoas 
tem que ir, simplesmente cumprir, né? E assim, todas as decisões são discutidas, são compartilhadas, então eu acho isso muito bom pra que o trabalho se desenvolva, diferente de lá na ponta alguém receber uma ordem e fazer uma tarefa ou ele participar de uma decisão e saber que ele vaifazer (G69).

O gestor reconhece a decisão compartilhada como importante para a gestão do trabalho, a partir da constatação de que o trabalhador precisa estar envolvido na formulação de práticas que façam sentido para ele. 0 espaço da escuta e da fala compartilhados no cotidiano dos serviços de saúde representa a possiblidade de compartilhamento de olhares e dizeres que podem ter a potência de propor mudanças práticas, tendo impacto tanto no território da gestão formal do trabalho quanto no da gestão do cuidado. Campos (2007, p. 235) reconhece essa gestão compartilhada como a gestão colegiada dos serviços de saúde, a cogestão, que se refere ao envolvimento de todos os atores, sejam eles gestores ou trabalhadores operantes, na elaboração de novas formas de gerir e organizar os serviços através de contratos de gestão, sendo considerada um "dispositivo desalienante".

Para Coêlho (2015, p. 53) "a cogestão experimentada na atenção básica, além da necessidade de encontros coletivos, fundou-se na construção dos dispositivos e concretização da clínica compartilhada", que pode ser compreendida como uma maneira de organizar os processos de trabalho com atuação abrangente e ampliada nos determinantes do processo saúde-doença, com a elaboração de projetos terapêuticos singulares. A cogestão apresenta-se como um modo de governar que "envolve o pensar e o fazer coletivo visando à democratização das relações no campo da saúde" (p. 82).

\section{Limites da gestão do trabalho}

A interferência das lideranças políticas do município representa um fator de descontentamento para o gestor, o que gera entraves para a consolidação do seu plano de trabalho, tendo o potencial de desordenar e reorganizar o fluxo de trabalho das equipes e os processos de tomada de decisão e autonomia dos gestores formais do trabalho.

É a questão política, muitas vezes vereador tenta manipular os cargos, tentam ditar um pouco as regras, tentam dificultar um pouco a nossa forma de trabalho $(\mathrm{G} 1)$.

O profissional que é do lado do prefeito ele age de uma forma pra ajudar, porque ele quer continuar, ele acha bom. Quem é contra faz de tudo pra derrubar o serviço, e por aívai, é dessa forma que a gente vê. Infelizmente a política $\left(\mathrm{G}_{7}\right)$.

O que perdura, em alguns municípios, é um regime de regulação político-clientelístico, representado pelo "atravessamento dos vereadores e de outras forças políticas locais no funcionamento do SUS”. Os gestores, em especial os secretários municipais de saúde, "estão tendo de enfrentar poderosas forças antirregulatórias ou contrarregulatórias, em particular a atuação dos atores políticos locais que fazem uso da saúde como parte de seus projetos político-partidário-eleitorais" (Cecílio; Carapinheiro; Andreazza, 2014, p. 95). 0 modo de operação desse regime de regulação está fortemente amparado na "pressão e barganha”, ou seja, o acesso aos serviços de saúde é garantido em troca de votos, sendo seu tempo de legitimação mais rápido em relação ao tempo do regime de regulação profissional ou governamental, sendo o primeiro efetuado por gestores e formuladores das políticas, e o segundo pelos trabalhadores dos serviços.

A rotatividade e a escassez de profissionais médicos são referidas como dificuldades para a manutenção das equipes e organização do trabalho. G65 evidencia o poder do modelo médico hegemônico e critica a superioridade do médico perante os outros profissionais da equipe, com dificuldade na gestão do trabalho desse profissional que resiste ao cumprimento da carga horária total e das normalizações requeridas na ESF.

O grande problema da Estratégia Saúde da Família hoje é a classe médica. A gente consegue manter o agente comunitário de saúde, a parte 
administrativa, enfermeiro, agora a parte médica é muito rotativa. Um mês eu tenho, em outro mês eu tenho que está providenciando outro médico. Hoje se tem uma ideia, a classe médica tem a ideia que a o médico é o topo da hierarquia. Primeiro que o médico não cumpre carga horária, tem que ficarno pé. [...] eu acho que se o enfermeiro cumpre carga horária de 40 horas semanais, o médico também tem que cumprir. Ena minha gestão, não cumpre, infelizmente eu corto o dia que ele não veio. Então ele trabalha dois meses comigo por eu cortar os pontos, corto o dia (G65).

Ney e Rodrigues (2012), ao analisarem os fatores que interferem na fixação do profissional médico na ESF, destacam motivos de insatisfação nos discursos dos trabalhadores, tais como: a infraestrutura das USFs; sobrecarga de trabalho; grande demanda espontânea e o atendimento de usuários não adscritos por solicitação de ocupantes de cargos políticos municipais; política municipal de gestão do trabalho no que se refere à inexistência de ações de educação permanente, salários considerados impróprios, vínculos empregatícios precários e a ausência de um Plano de Cargos, Carreiras e Salários (PCCS) que garanta ascensão e desenvolvimento profissional; e a desarticulação da rede de atenção à saúde do município, que impede ou mesmo dificulta o percurso dos usuários pelos diferentes níveis de atenção. A desvalorização salarial relatada pelos médicos da ESF resulta na busca por outros vínculos de trabalho, o que impede o cumprimento da carga horária requerida para a ESF e compromete a qualidade da atenção à saúde.

Cecílio e Andreazza (2007, p. 205), em uma pesquisa realizada entre 2005 e 2007 , com o objetivo de analisar as relações entre gestores estaduais e municipais na construção do processo de regionalização, evidenciam que os gestores não conseguem realizar a gestão do trabalho médico, com controle de horário e produtividade, visto que a categoria impõe à gestão dos municípios e estados um controle de barganha aliado à baixa disponibilidade de profissionais e à alta rotatividade que dificulta a fixação do médico. De acordo com os autores, os gestores reconhecem que a "baixa adesão dos médicos ao projeto SUS" relaciona-se à inoperância da rede de serviços e é evidenciada pelos encaminhamentos excessivos e desnecessários aos especialistas, em detrimento do "despreparo técnico". Assim, afirmam que será necessária a implementação de novas "regras do jogo", construídas em bases dialógicas e negociadas pelos atores, mas que poderão ser produtoras de grandes embates entre gestores e médicos, visto que poderão requerer a reorganização do trabalho dos últimos, com observância de princípios legais, como o cumprimento da carga horária requerida.

0 gestor reconhece a desorganização e a inoperância da rede de serviços de saúde do município e constata que a materialidade da gestão só é possível na dinâmica de funcionamento das redes de atenção à saúde, o que reafirma a reflexão de Franco (2013) de que existe uma imanência entre as redes e o processo de trabalho em saúde.

Olha, facilidade eu não tenho. A gente basicamente mata um leão a cada dia, porque é a especialidade que a gente não consegue, o usuário veme a gente trabalha com ele, trabalha um pouco essa questão da espera, passa um e-mail, envia e vê o que tá acontecendo. Às vezes o usuário precisa de uma consulta urgente e a gente não tem e conversa com o médico e ele vai, cede e atende, entendeu. Encaminha esse paciente pra algum serviço, então, assim, a gente não tem muita facilidade, porque a gente não tem uma gama de oferta muito grande (G63).

Ao analisar a constituição das redes no quesito acesso e consumos de serviços de saúde, o que existe é uma desarticulação entre os diferentes tempos: dos gestores, trabalhadores e usuários. A quimera da atenção básica, enquanto imagem objetivo no campo do sonho ou fantasia, prevê uma rede de serviços universal, resolutiva, cuidadora e integral, sem frequentemente levar em consideração os atravessamentos reais no cotidiano, como a produção de redes alternativas e operantes pelos trabalhadores, usuários, gestores e tantos outros autores, que nem sempre convergem para os mesmos interesses (Cecílio, 2012, p. 284). Nesse processo, os gestores experienciam um "tempo das possibilidades", através da busca permanente da 
adequada relação entre a oferta e a demanda, buscando a racionalização do uso dos tempos de acesso e consumo dos serviços. Os profissionais de saúde estão situados no tempo de cuidado, e os usuários, no tempo das necessidades, marcado principalmente pela experiência individual da doença. Assim, esses diferentes tempos, em geral são díspares e geram ruídos na operacionalização do sistema de saúde, de forma que os gestores estão atentos a uma demanda que parece estar equivocada; visto a inoperância da rede de serviços, os trabalhadores culpabilizam os gestores pela demora na disponibilização dos serviços e os usuários pelo imediatismo de suas demandas, determinando sua necessidade como imperativa.

O gestor está imerso em um regime de regulação governamental que vivencia a demanda crescente pelo consumo dos serviços de saúde, e uma rede de atenção à saúde que não cresce na mesma velocidade, especialmente por aspectos financeiros e político-administrativos. Ao mesmo tempo, se distancia do espaço da micropolítica do processo de trabalho em saúde, o que torna invisível as redes e fluxos produzidos por trabalhadores e usuários e que, em essência, tem grande potência na organização das redes vivas em saúde. Magalhães (2014) afirma que as redes de atenção à saúde sofrem grande impacto pelo acesso ampliado na atenção básica à saúde sem clareza dos fluxos entre os serviços, principalmente, com a expansão da ESF a partir da década de 90.

Merhy e colaboradores (2014, p. 154) ampliam a análise das redes de atenção à saúde para além da previsibilidade racional proposta pela Constituição Federal de 88 e pelas leis orgânicas do SUS, propondo a ideia das redes vivas, que contemplam as diferentes subjetividades dos atores envolvidos na produção do cuidado, reconhecendo que a rede de serviços de saúde não é única em seu regime regulatório governamental; ao contrário, opera em diferentes fluxos, como "redes vivas em produção", já que é produzida por todos os atores em cena, o que dificulta o controle regulatório proposto pela gestão em seu caráter meramente macropolítico. Assim, “a discussão de redes de cuidado em saúde, olhada a partir da macropolítica, tem baixa potência por não abarcar a dimensão micropolítica das experiências cotidianas" (Merhy et al., 2014, p. 156).
Aliados à inoperância das redes de atenção à saúde, surgem nos discursos aspectos relacionados ao financiamento e às legislações que regem os gastos na gestão pública municipal, os quais são apontados como dificuldades de condução das atividades de gestão do trabalho na ESF. A morosidade do serviço público é constatada na obrigatoriedade da realização de licitações para compra de materiais e celebração de contratos, e em razão da Lei de Responsabilidade Fiscal (LRF), número 101/200o, que limita os gestores na contratação de trabalhadores.

Hoje o principal problema da secretaria é a lei da responsabilidade fiscal. Enquanto nós, equipes de ESF, não conseguirmos não desonerar a folha e ter uma forma de contratação que a gente não conte na lei da responsabilidade fiscal, a gente está amarrado. Então todos os problemas do município passam pelo financeiro. Estão agarradas no financeiro (G18).

Principal dificuldade é o processo licitatório, a burocratização porque ele énecessário, porém, o tempo da burocracia é um tempo muito grande, então isso acaba prejudicando pra gente tá tendo material em tempo hábil, medicação em tempo hábil. Poderia ser uma coisa menos burocrática pra poder não ter tanta demora na espera porque o usuário não consegue entender porque nós temos que esperar esse processo e é feita a cobrança tanto por parte das equipes tanto por parte do usuário ( $\left.\mathrm{G}_{45}\right)$.

Mendes (2015) analisa o limite de gastos com os trabalhadores por meio da LRF como uma barreira para a construção do SUS, considerando que o município não deve ultrapassar $54 \%$ da receita corrente líquida com gasto com pessoal. 0 autor reafirma que a LRF tem contribuído para a contratação de serviços de terceiros para a gestão e provimento do trabalho na saúde, como as Organizações Sociais da Saúde ou Organizações Civis de Interesse Público, o que deveria ser atribuição exclusiva da gestão municipal. A referida Lei deveria ser revista no quesito contratação de profissionais para a ESF e outros serviços de saúde, já que uma parte dos recursos 
financeiros destinados à contratação e pagamento dos trabalhadores é oriunda de financiamento federal e estadual, e não apenas de recursos próprios do município.

Pierantoni et al. (2004), em um estudo sobre a capacidade gestora de recursos humanos em instâncias locais de saúde, afirmam que a avaliação da autonomia de gestão dos gestores do trabalho nos municípios revela ser muito baixa ou inexistente, visto que a tomada de decisão sobre elementos do trabalho das equipes, por exemplo, na contratação e utilização de recursos financeiros, está condicionada às burocracias internas, alheias à governabilidade do gestor. Os gestores em cargos de autodireção nas instâncias locais de saúde não dispõem de instrumentos e técnicas de negociação no interior da instituição que sejam capazes de sobrepor às estruturas de mando dos demais dirigentes municipais da saúde.

A descentralização da gestão dos serviços no âmbito do SUS propiciou maior autonomia operacional para os municípios. No entanto, a complementação financeira requerida aos municípios para o desenvolvimento de ações e programas constitui um dificultador, principalmente naqueles de pequeno e médio porte. Ou seja, de acordo com os gestores, a arrecadação e o montante de recursos municipais destinados à saúde são insatisfatórios para a condução da rede de atenção à saúde, o que gera a destinação dos recursos disponíveis para níveis de atenção considerados prioritários, como a média e alta complexidade, com comprometimento da organização da Atenção Primária como porta de entrada para o sistema de saúde.

O custeio da atenção primária é o desafio realizar. O governo federal já tem a sua contribuição, mas mesmo assim pra tá custeando todos os vínculos, todas as necessidades da ESFo município tem que contribuir muito com recurso próprio para garantir essa assistência. O município recebe uma arrecadação pequena e é onde acaba descompensando um pouco e investindo mais na média e alta complexidade. $O$ desafio é gerir os recursos com o objetivo de atender a todos, a toda a necessidade da população $\left(\mathrm{G}_{47}\right)$.
A descentralização da gestão dos serviços de saúde não representou um aumento da capacidade gestora para a esfera municipal, devido a restrições jurídico-legais e políticas, o que gerou arranjos diversos de condução dos serviços pelos gestores, que experienciam a limitação do seu campo de intervenção, ao mesmo tempo em que identificam demandas necessárias para a reformulação do sistema (Fleury, 2014).

Para os gestores, o perfil de comprometimento no trabalho dos profissionais da ESF constitui um requisito imprescindível para a condução e resolutividade das ações de atenção à saúde, por meio da identificação pessoal do trabalhador com a lógica do cenário de trabalho e com as demandas de saúde dos usuários, o que para eles independe da formação profissional básica ou complementar.

Eles não têm perfil. $\varepsilon$ isso é muito importante. Eu fazer uma faculdade, fazer uma pós-graduação, um mestrado, não indica nada. Eu acho que tem que ter perfil. Pra pessoa ser uma enfermeira, um médico de família, um enfermeiro da família tem que ter perfil e infelizmente aqui tá difícil, a gente conta nos dedos os profissionais com perfil $\left(\mathrm{G}_{7}\right)$.

O principal é o profissional médico, que aí vem desde não ter perfil, só quer ganhar dinheiro, não ter perfil de trabalhar em saúde da família (G10).

Em um estudo sobre a avaliação da gestão do trabalho na ESF no estado do Amazonas, Pires (2012) identifica, através da análise dos discursos dos trabalhadores, que a opção pelo trabalho nessa Estratégia se deve às questões referentes ao mercado de trabalho e não ao perfil considerado adequado para o desenvolvimento dessas questões. Relatam fatores de descontentamento no trabalho na ESF, como: sobrecarga de trabalho, desvalorização, interferência dos interesses políticos na permanência e contratação dos profissionais, vínculos precários de trabalho, alta rotatividade e déficit de trabalhadores.

Segundo Franco (2013), um dos desafios da gestão do trabalho, é envolver o trabalhador em um projeto comum técnico-político-ético, já que existem 
sujeitos plenos e singulares, e considerando que, geralmente, os gestores do trabalho exercem uma gestão normativa de mando que garante apenas a formação de trabalhadores serializados que repetem práticas legitimadas e ultrapassadas. Assim,

os trabalhadores são equiparados a um insumo para o funcionamento dos serviços de saúde, quando na verdade ele é o maior protagonista da produção do cuidado, é sujeito ativo que opera com seus saberes, é desejante, tem projetos, expectativas e atua no mundo do trabalho e cuidado com suas caixas de ferramentas adquiridas na formação, e sobretudo na experimentação do mundo do trabalho e da vida, e isso é que vai marcando sua atividade (Franco, 2013, p. 250).

Os gestores caricaturam a ação dos trabalhadores no cenário real de práticas, caso a mesma esteja contrária às normatizações e disciplinamento que regem o trabalho em saúde nos municípios, como sendo um "perfil" inadequado de trabalho para a ESF. Feuerwerker (2014, p. 103) ressalta que "é preciso problematizar a questão de que o complexo mundo do trabalho não é um lugar do igual, mas da multiplicidade, do diverso e da diferença, da tensão e da disputa”. A autora afirma que é necessário, no bojo das organizações e dos processos decisórios, "reconhecer a diversidade, os processos de formação de subjetividades, a forma singular de produção do cuidado" e a potência inscrita na dinâmica da práxis.

A formação em serviço dos profissionais da ESF é identificada como uma prioridade para a melhoria do cotidiano de trabalho. No entanto, os gestores reconhecem que ela inexiste no município de forma sistematizada e organizada, e a associam a um limite da constituição da gestão em saúde, devido à rotatividade de profissionais nas equipes, decorrente de fatores intrínsecos à gestão do trabalho, como vínculos empregatícios; e extrínsecos, como a interferência política na contratação de trabalhadores.

O que eu tenho identificado é que a gente não tem ainda uma equipe de educação permanente, né. Meu problema maior na gestão do trabalho aqui é justamente a equipe, uma equipe de educação permanente, um núcleo que pudesse ajudar $\left(\mathrm{G}_{59}\right)$.

A oferta da educação permanente constitui uma importante ferramenta de fomento à gestão do trabalho, contribuindo para a valorização do trabalhador e de sua prática e para a reorganização do processo de trabalho em saúde, com a apropriação de conhecimentos significativos sobre o cotidiano do trabalho que terão potência de instituir processos de autoanálise e autogestão por parte dos atores no cenário da micropolítica. Para a corrente do institucionalismo, o processo de autoanálise representa a produção de um saber e o conhecimento de seus recursos e propicia a auto-organização de forças capazes de transformar as condições de existência, estimulando processos autogestionários das práticas em análise, a partir do empoderamento do trabalhador e do protagonismo do seu trabalho (Baremblitt, 1996). Assim, a "ausência ou insuficiência de incentivos para qualificação profissional pode contribuir para dificuldades de manutenção e desmotivação dos profissionais na Atenção Básica” (Seidl, 2014, p. 106).

A prática da educação permanente tem a potência de produzir diferentes efeitos no espaço da USF, como: problematização do processo de trabalho que institui reflexões que podem ameaçar a gestão caso esta não deseje problematizar processos decisórios; fortalecimento da gestão por meio de disputas de projetos, desterritorialização e construção de coletivos que desejam transformar o modo de produzir saúde; e valorização dos trabalhadores no exercício de sua autonomia, visando produzir encontros fecundos entre a equipe e os usuários (Feuerwerker, 2014).

\section{Considerações finais}

Conclui-se que este estudo permitiu a análise das potencialidades e limites da gestão do trabalho na ESF, a partir dos discursos dos gestores que ocupam cargos de autodireção na gestão municipal de saúde no estado do ES, com um enfoque nas nuances do espaço de imanência entre macro e micropolítica dos processos de gestão e trabalho. 
A caracterização dos gestores revela um perfil sociodemográfico com predomínio de trabalhadores do sexo feminino, com idade média de 38 anos e ensino superior completo. 0 perfil profissional revela o predomínio de ocupantes do cargo de secretário municipal de saúde, sendo que cerca de 50\% dos gestores não possuem formação específica na área de gestão em saúde e aproximadamente 55\% não recebeu nenhuma formação para o cargo.

Apontam como dificuldades do cotidiano de trabalho a interferência de lideranças políticas, a rotatividade e dificuldade de fixação do profissional médico nas equipes, a inoperância da rede de serviços de saúde, a burocratização do serviço público instituída por leis de controle de gastos da gestão municipal, o perfil de atuação dos trabalhadores na ESF e a formação em serviço. Em consequência, o gestor do trabalho detém pouca capacidade gestora no processo de tomada de decisão, visto que sua prática é atravessada por linhas de mando das lideranças políticas no município que dificultam o acesso direito aos recursos financeiros para aquisição de recursos materiais e contratação de profissionais.

Destacam-se, nos discursos, elementos que sinalizam uma prática de gestão por disciplinamento e controle das práticas dos trabalhadores através da obtenção de resultados, fundamentada em atos mandatórios e normalizadores do trabalho dito prescrito, trabalho morto, que amputa o trabalhador da sua autonomia e inventividade. 0 que está em jogo e o que impera é o tempo do gestor enquanto instituição de atos em saúde, serializados pelas portarias ministeriais de concepção do modelo da ESF. Há erros de saída e de chegada, pois está claro que o poder de decisão e condução dos processos, por parte da gestão formal, está se sobrepondo à ideia de potência da gestão citada como compartilhada por todos os atores em cena. Surge a figura do gestor moral/funcional, que é detentor de ações de gerência que acondicionam, regulam, conduzem e regem os processos de trabalho, partindo do pressuposto de que os gestores formais são os protagonistas na organização dos diferentes trabalhos.

Como potência na condução do trabalho na ESF, os gestores identificam as relações de vínculo entre trabalhadores e usuários, disponibilidade satisfatória de insumos e equipamentos, aspectos estruturais das USFs, oferta de profissionais para comporem as equipes, a lógica de organização do trabalho coletivo, cobrança de metas e resultados e o Programa Mais Médicos. Para o universo deste estudo, o modelo tecnoassistencial médico hegemônico é o modelo vigente paralelo à ESF na vivência da gestão em saúde, de forma que indicadores quantitativos de números de consultas médicas e provisão de profissionais médicos na ESF são avaliados como o cerne da gestão do trabalho. A gestão do trabalho médico transita como um limite e uma potencialidade da gestão na ESF, estando o gestor refém desse profissional através da ingerência de aspectos normativos do modelo de atenção, como a cobrança da carga horária e o controle do número de atendimentos.

O trabalho coletivo, enquanto trabalho em equipe, é valorizado pelos gestores, mas se desvela nos discursos como um momento de trabalho determinado pelas coordenações afluentes da gestão formal. 0 trabalho em equipe, conforme emerge nos discursos, faz uma alusão ao trabalho em redes, que, mesmo que modelares ou inovadoras, podem representar conexões entre os sujeitos do trabalho, em processos de produção contínua de democratização e ética nas relações de trabalho.

Na perspectiva do gestor, a inovação dos processos de gestão está relacionada a uma aposta na organização dos processos de trabalho na ESF e na implementação da gestão compartilhada, através da normatização do trabalho com a construção de protocolos, definição de metas e avaliação de resultados e, ao mesmo tempo, por meio da proposição de espaços coletivos de decisão e diálogo que sensibilizem o trabalhador para o projeto proposto pela gestão formal. Inovar, para os gestores em estudo, representa mobilizar os trabalhadores com base em um centralismo político que garante ao gestor formal a decisão final e definição dos rumos, já que as equipes detém pouca governabilidade em relação à definição de metas e indicadores.

Nesse sentido, o maior desafio na ativação da potência para a ação do trabalhador consiste na inovação por meio de novos modos de produzir a gestão do trabalho, com base na cogestão com es- 
paços dialógicos de tomada de decisão que tenham a potência de disparar novas formas de vida no gestor e no trabalhador, através da democratização da tomada de decisão. O profissional deixa de ser concebido como um mero recurso humano, para ser pensado como um trabalhador operante, que é gestor do seu próprio trabalho, e que governa e disputa a condução das ações e projetos com as ferramentas que dispõem.

\section{Referências}

BAREMBLITT, G. Compêndio de análise institucional e outras correntes: teoria e prática. Rio de Janeiro: Rosa dos Tempos, 1996.

BARROS, M. E. B. Trabalhar: usar de si-sair de si. Interface-comunicação, Saúde, Educação, São Paulo, v. 11, n. 22, p. 345-363, 2007.

BRASIL. Ministério da Saúde. Secretaria de Assistência à Saúde. Coordenação de Saúde da Comunidade. Saúde da família: uma estratégia para a reorientação do modelo assistencial. Brasília, DF, 1997.

BRASIL. Lei No 12.871, de 22 de outubro de 2013. Institui o Programa Mais Médicos, altera as Leis no 8.745, de 9 de dezembro de 1993, e no 6.932, de 7 de julho de 1981, e dá outras providências. Diário Oficial da União, Brasília, DF, 23 out. 2013.

CAMPOS, G. W. S. Subjetividade e administração de pessoal: considerações sobre modos de gerenciar o trabalho em equipes de saúde. In: MERHY, E. E.; ONOCKO, R. (Org.). Agir em Saúde: um desafio para o público. São Paulo: Hucitec, 2007. p. 229-266.

CECILIO, L. C. O. Escolhas para inovarmos na produção do cuidado, das práticas e do conhecimento: como não fazermos "mais do mesmo"? Saúde e Sociedade, São Paulo, v. 21, n. 2, p. 280-289, 2012.

CECILIO, L. C. O.; ANDREAZZA, R. O gestor municipal na atual etapa de implantação do SUS: características e desafios. RECIIS, Rio de Janeiro, v. 1, n. 2, p. 200-207, 2007.
CECILIO, L. C. O.; CARAPINHEIRO, G.; ANDREAZZA, R. (Org.). Os mapas do cuidado: o agir leigo na saúde. São Paulo: Hucitec, 2014. COÊLHO, B. P. Reformulação da clínica e gestão na saúde: subjetividades, política e invenção de práticas. São Paulo: Hucitec, 2015.

COLLAR, J. M. et al. Formulação e impacto do Programa Mais Médicos na atenção e cuidado em saúde: contribuições iniciais e análise comparativa. Saúde em Redes, Rio de Janeiro, v. 1, n. 2, p. 43-56, 2015.

FEUERWERKER, L. C. M. Micropolítica e saúde: produção do cuidado, gestão e formação. Porto Alegre: Rede Unida, 2014.

FLEURY, S. Democracia e inovação na gestão local da saúde. Rio de Janeiro: Fiocruz, 2014.

FORTUNA, C. M. et al. Alguns aspectos do trabalho em saúde: os trabalhadores e os processos de gestão. Saúde em Debate, Rio de Janeiro, v. 26, n. 62, p. 272-281, 2002.

FRANCO, T. B. As redes na micropolítica do processo de trabalho em saúde. In: PINHEIRO, R.; MATTOS, R. A. (Org.). Gestão em Redes. Rio de Janeiro: LAPPIS/IMS/UERJ, 20o6. p. 459-473.

FRANCO, T. B. O trabalhador de saúde como potência: ensaio sobre a gestão do trabalho. In: FRANCO, T. B.; MERHY, E. E. Trabalho, produção do cuidado e subjetividade em saúde. São Paulo: Hucitec, 2013. p. 243-251.

FRANCO, T. B.; MERHY, E. E. Programa de Saúde da Família (PSF): contradições de um programa destinado à mudança do modelo tecnoassistencial. In: MERHY, E. E. (Org.). O trabalho em Saúde: olhando e experienciando o SUS no cotidiano. São Paulo: Hucitec, 2003. p. 55-124.

GIL, C. R. R. Atenção Primária, atenção básica e saúde da família: sinergias e singularidades do contexto brasileiro. Cadernos de Saúde Pública, Rio de Janeiro, v. 22, n. 6, p. 1171-1181, 2006.

GIOVANELLA, L.; MENDONÇA, M. H. M. Atenção Primária à Saúde. In: GIOVANELLA, L. et al. (Org.). 
Políticas e sistema de saúde no Brasil. Rio de Janeiro: Fiocruz, 2012. p. 493-545.

MAGALHÃES, H. M. J. Redes de Atenção à Saúde: rumo à integralidade. Divulgação em Saúde para Debate, Rio de Janeiro, n. 52, p. 153-164, 2014.

MAGNAGO, C.; PIERANTONI, C. R. Dificuldades e estratégia de enfrentamento referentes à gestão do trabalho na Estratégia Saúde da Família, na perspectiva dos gestores locais: a experiência dos municípios do Rio de Janeiro (RJ) e Duque de Caxias (RJ). Saúde em Debate, Rio de Janeiro, v. 39, n. 104, p. 9-17, 2015.

MENDES, A. Limite de gasto com pessoal na saúde pela LRF: uma barreira à construção do SUS público, integral e de qualidade. Brasília, DF: 2015. Disponível em: <http://bit.ly/2fOsZq2>. Acesso em: 20 set. 2015 .

MENDONÇA, M. H. M. et al. Desafios para gestão do trabalho a partir de experiências exitosas de expansão da Estratégia de Saúde da Família. Ciência \& Saúde Coletiva, Rio de Janeiro, v. 15, n. 5, p. 2355-2365, 2010.

MERHY, E. E. $\mathrm{O}$ ato de governar as tensões constitutivas do agir em saúde como desafio permanente de algumas estratégias gerenciais. Ciência \& Saúde Coletiva, Rio de Janeiro, v. 4, n. 2, p. 305-314, 1999.

MERHY, E. E. et al. Redes vivas: multiplicidades girando as existências, sinais da rua.
Implicações para a produção do cuidado e a produção do conhecimento em saúde. Divulgação em Saúde para Debate, Rio de Janeiro, n. 52, p. 153-164, 2014.

MINAYO, M. C. S. O desafio do conhecimento: pesquisa qualitativa em saúde. 14 ed. São Paulo: Hucitec, 2014.

NEY, M. S.; RODRIGUES, P. H. A. Fatores Críticos para a fixação do médico na Estratégia Saúde da Família. Physis, Rio de Janeiro, v. 22, n. 4, p. 12931311, 2012.

PAIM, J. S. Modelos de atenção à Saúde no Brasil. In: GIOVANELLA, L.; ESCOREL, S.; LOBATO, L. V. C. et al. (Org.). Políticas e Sistema de Saúde no Brasil. 2 ed. Rio de Janeiro: FIOCRUZ, 2012. p. 459-491.

PIERANTONI, C. R.; VARELLA, T. C.; FRANÇA, T. Recursos humanos e gestão do trabalho em saúde: da teoria para a prática. In: BARROS, A. F. R. (Org). Observatório de recursos humanos em saúde no Brasil: estudos e análise. Brasília, DF: Ministério da Saúde, 2004, p. 51-70.

PIRES, R. O. M. Avaliação da Gestão do Trabalho em Saúde da Família. 1 ed. Curitiba: Appris, 2012.

SEIDL, H. et al. Gestão do trabalho na Atenção Básica em saúde: uma análise a partir da perspectiva das equipes participantes do PMAQAB. Saúde em Debate, Rio de Janeiro, v. 38, p. 94108, 2014, Número Especial.

\section{Contribuição dos autores}

Todos os autores contribuíram com a análise e interpretação dos dados e redação do artigo. Galavote e Lima conceberam e delinearam o projeto e aprovaram a versão a ser publicada.

Recebido: 15/01/2016

Reapresentado: 08/07/2016

Aprovado: 25/07/2016 